\title{
Significance of coagulation and fibrinolysis markers for benign and malignant soft tissue tumors
}

\author{
Kunihiro Asanuma ${ }^{1 *}$ (D), Tomoki Nakamura ${ }^{1}$, Tomohito Hagi ${ }^{1}$, Takayuki Okamoto², Kouji Kita', Koichi Nakamura', \\ Yumi Matsuyama', Keisuke Yoshida', Yumiko Asanuma' and Akihiro Sudo'
}

\begin{abstract}
Background: The intimate relationship between coagulation and fibrinolysis in malignant tumors is a well-known phenomena, with the malignant phenotype enhancing coagulation and fibrinolysis. We hypothesized that soft tissue sarcoma (STS) affects the expression of coagulation and fibrinolysis markers, which could be used to distinguish STS from benign soft tissue tumors. We analyzed the correlations between plasma levels of D-dimer (DD), plasmin-a2 plasmin inhibitor complex (PIC), soluble fibrin (SF), and thrombin-antithrombin III complex (TAT) in benign soft tissue tumors and STS to elucidate whether these markers can be used to predict STS.

Methods: Plasma DD, PIC, SF and TAT levels in primary soft tissue tumors (benign 67, STS 68) were measured before biopsy or treatment. The marker levels were analyzed and compared to various clinicopathological parameters.

Results: In malignancy (STS), the average DD, PIC and SF levels were significantly higher than in benign tumors. Multivariate logistic analysis of continuous variables indicated that only PIC exhibited a significant difference (OR: 24.5, 95\% Cl: $3.55-170, p=0.0012$ ). Receiver operating characteristic curve analysis produced area under the curve values for DD: 0.691, PIC: 0.784 , SF: 0.734 and TAT: 0.588. Youden's index was used to establish thresholds of 0.37 (DD), 0.80 (PIC), 0.90 (SF) and 0.82 (TAT). Threshold values for PIC and SF indicated high specificity $(0.881,0.791)$ and high positive predictive value $(0.818,0.745)$, respectively. The highest accuracy value among the markers was observed for PIC (0.704). Significant differences in multivariate analysis of binary variables were demonstrated by categorizing low and high groups based on their threshold, PIC ( $\geq 0.80)(\mathrm{OR}: 3.36,95 \% \mathrm{Cl}: 1.19-9.43, p=0.0212)$ and SF ( $\geq 0.90)$ (OR: $2.63,95 \% \mathrm{Cl}: 1.04-6.66, p=0.0404)$.
\end{abstract}

Conclusions: Of the coagulation and fibrinolysis markers studied, increased PIC levels were related to STS and over $0.80 \mathrm{PIC}$ was the most suitable for the prediction of STS, which, along with other diagnostic tools, represents a helpful subsidiary tool for the prediction of STS.

Keywords: Soft tissue sarcoma, Metastasis, Prognosis, Coagulation, Fibrinolysis, D-dimer, Plasmin-a2 plasmin inhibitor complex, Soluble fibrin, And thrombin-antithrombin III complex

\footnotetext{
* Correspondence: kasanum@gmail.com

'Department of Orthopedic Surgery, Mie University School of Medicine,

2-174 Edobashi, Tsu City, Mie 514-8507, Japan

Full list of author information is available at the end of the article
}

C C The Author(s). 2021 Open Access This article is licensed under a Creative Commons Attribution 4.0 International License, which permits use, sharing, adaptation, distribution and reproduction in any medium or format, as long as you give appropriate credit to the original author(s) and the source, provide a link to the Creative Commons licence, and indicate if changes were made. The images or other third party material in this article are included in the article's Creative Commons licence, unless indicated otherwise in a credit line to the material. If material is not included in the article's Creative Commons licence and your intended use is not permitted by statutory regulation or exceeds the permitted use, you will need to obtain permission directly from the copyright holder. To view a copy of this licence, visit http://creativecommons.org/licenses/by/4.0/ The Creative Commons Public Domain Dedication waiver (http://creativecommons.org/publicdomain/zero/1.0/) applies to the data made available in this article, unless otherwise stated in a credit line to the data. 


\section{Background}

It is well-known that malignant tumors are highly correlated with coagulation and fibrinolysis. Many tumor cells express tissue factor (TF) and urokinase-type plasminogen activator receptor (uPAR) on their surface. TF is a coagulation factor that activates the extrinsic coagulation cascade, thereby leading to the generation of thrombin and fibrin. Thrombin stimulates tumor cell adhesion to platelets, endothelial cells, extracellular matrix proteins, as well as tumor cell mitogenesis $[1,2]$. Previous reports of breast cancer showed that thrombin increased invasive activity through the thrombin receptor and that inhibition of protease activated receptor-1 (PAR-1) expression reduced invasive potential [3, 4]. Thus, the effects of thrombin may account for the observation that thrombin-pretreated melanoma cells markedly enhance pulmonary metastasis in vivo [1]. In contrast, uPAR, a main fibrinolytic factor of cancer cells, forms a complex with urokinase-type plasminogen activator (uPA) and converts plasminogen into plasmin. The generated plasmin induces a variety of proteolyses, including fibrin degradation. Moreover, plasmin not only cleaves extracellular matrices but also activates pro-MMPs [5]. Overexpression of UPAR in breast cancer enhanced tumor invasion, growth and metastasis [6]. Additionally, breast cancer patients with high expression of uPA and plasminogen activator inhibitor-1 (PAI-1) in tumor tissues had lower survival than the low expression group [7]. Thus, the malignant phenotype appears to enhance coagulation and fibrinolysis.

The state of coagulation and fibrinolysis can be evaluated by examining several markers such as thrombinantithrombin III complex (TAT), soluble fibrin (SF), plasmin and alpha 2 plasmin inhibitor complex (PIC) and D-dimer (DD). These markers were examined in this study. After thrombin is generated by activation of the coagulation cascade, part of it forms a complex with antithrombin III (TAT) [1]. Some thrombin cleaves fibrinogen and the resultant fibrin monomers can form a complex with fibrinogen (SF) [2]. Furthermore, fibrinolysis can be evaluated by assessing fibrinolysis markers such as plasmin and alpha 2 plasmin inhibitor complex (PIC) or D-dimer. After plasmin is generated from plasminogen, it can form a complex with alpha 2 plasmin inhibitor [3]. DD consists of two cross-linked D fragments that generated by degradation of fibrin following proteolysis by plasmin [4], and can be used as an indication of plasmin-induced fibrinolysis after fibrin formation [5].

Thus, we hypothesized that soft tissue sarcoma (STS) could affect the expression of coagulation and fibrinolysis markers, which could be used to distinguish STS from benign soft tissue tumors. To examine the predictive value of markers of coagulation or fibrinolysis for discriminating between benign soft tissue tumors and STS, we analyzed the correlation between plasma levels of TAT, SF, PIC or DD and clinical parameters in soft tissue tumor patients.

\section{Methods \\ Patients}

A total of 135 patients (76 men and 59 women) with primary soft tissue tumors who visited Mie University Hospital from 2012 to 2014 were enrolled in this study. Patients who had local recurrence, were referred for additional resection after inadequate resection in a previous hospital, or had trauma, surgical treatment, thrombosis and disseminated intravascular coagulation (DIC) were excluded from this study. Histopathological diagnoses based on the AJCC (American Joint Committee on Cancer) system were verified by independent pathologists. Blood samples from all patients were obtained (stored in sodium citrate tubes) before biopsy or treatment.

The levels of D-dimer (DD: $\mu \mathrm{g} / \mathrm{ml})$, plasmin- $\alpha 2$ plasmin inhibitor complex (PIC: $\mu \mathrm{g} / \mathrm{ml}$ ), soluble fibrin (SF: $\mu \mathrm{g} / \mathrm{ml}$ ) or thrombin-antithrombin III complex (TAT: ng/ $\mathrm{ml}$ ) in plasma were quantified using a chemiluminescent enzyme immunoassay or latex photometric immunoassay. Written, informed consent was obtained from each patient. For patients below the age 19 years, informed consent was obtained from their parents or legal guardian. This study was approved by the Ethics Committee of the Mie University Graduate School of Medicine (approval number: 1310). All procedures performed in studies involving human participants were in accordance with the ethical standards of the Ethics Committee of Mie University and with the Declaration of Helsinki.

\section{Statistical analysis}

Clinicopathological analysis was performed to compare the plasma levels of TAT, SF, PIC or DD to various clinical parameters using the Mann-Whitney test or Kruskal Wallis test for quantitative data and Fisher's exact test for qualitative data. To evaluate the threshold for detecting STS, receiver operating characteristic (ROC) curves were generated. ROC curves were created by plotting sensitivity on the $y$-axis and the false positive rate (1-specificity) on the $\mathrm{x}$-axis. The area under the curve (AUC) of the ROC curves was assessed to measure the effectiveness of TAT, SF, PIC or DD levels as markers of malignancy. Univariate and multivariate logistic regression analyses were used to screen and estimate risk factors for malignancy of soft tissue tumors. $P<0.05$ was considered significant. The EZR software program was used for statistical analyses [6]. 


\section{Results}

\section{Patient and tumor characteristics}

The average age of the patients was 55.9 years (range: 12-92 years), and the median tumor size was $10.3 \mathrm{~cm}$ (range: $1-31 \mathrm{~cm}$ ). The distribution between benign and STS for patients $\geq 60$ years of age and patients with tumor size $\geq 10 \mathrm{~cm}$ were significantly different (Table 1 ).

Histopathological diagnoses were as follows: 67 benign tumors were made up of 26 lipomas, 13 schwannomas, 7 fibromatosis, 5 chronic expanding hematomas, 3 neurofibromas, 3 pigmented villonodular synovitis (PVNS), and 10 others; while the 68 STS were made up of 29 liposarcomas (17 well-differentiated liposarcomas, 6 dedifferentiated liposarcomas, and 6 myxoid liposarcomas), 13 undifferentiated pleomorphic sarcomas, 9 myxofibrosarcomas, 4 leiomyosarcomas, 3 synovial sarcomas, 3 malignant peripheral nerve sheath tumors, and 7 others.

\section{DD, PIC, SF and TAT levels}

DD, PIC, SF, and TAT levels were compared based on clinical characteristics. Sex, tumor location and tumor depth were not significantly different according to DD, PIC, SF, and TAT levels. Patients with age $\geq 60$ years showed significantly elevated levels of DD, PIC, SF and TAT. Patients with tumor size $\geq 10 \mathrm{~cm}$ showed significantly higher levels of DD, PIC and SF (Table 2). In the malignancy group (STS), average DD, PIC and SF levels were significantly higher than in the benign tumor group, according to the Mann-Whitney test (Fig. 1). In particular, chronic expanding hematoma and PVNS have increased risk for alterations in thrombosis or fibrinolysis status. DD, PIC, SF, and TAT levels in chronic expanding hematoma were $3.13 \pm 4.57,0.62 \pm 0.29$, $1.20 \pm 1.33$ and 3.26 \pm 4.59 , respectively. Only DD showed a significantly higher level than the other benign tumors $(P=0.000514$, Mann-Whitney test) or STS $(P=$

Table 1 Patient characteristics in benign soft tissue tumors and STS

\begin{tabular}{|c|c|c|c|c|c|}
\hline \multicolumn{2}{|l|}{ Characteristics } & \multirow{2}{*}{$\begin{array}{l}n \\
76\end{array}$} & \multirow{2}{*}{$\begin{array}{l}\text { Benign } \\
40\end{array}$} & \multirow{2}{*}{$\begin{array}{l}\text { STS } \\
36\end{array}$} & \multirow{2}{*}{$\begin{array}{l}p \text {-value } \\
0.489\end{array}$} \\
\hline Sex & Male & & & & \\
\hline & Female & 59 & 27 & 32 & \\
\hline \multirow[t]{2}{*}{ Age } & $<60$ & 75 & 49 & 26 & 0.0000603 \\
\hline & $\geq 60$ & 60 & 18 & 42 & \\
\hline \multirow[t]{2}{*}{ Tumor size } & $<10$ & 78 & 48 & 30 & 0.00165 \\
\hline & $\geq 10$ & 57 & 19 & 38 & \\
\hline \multirow[t]{2}{*}{ Location } & Extremity & 68 & 39 & 29 & 0.0859 \\
\hline & Trunk & 67 & 28 & 39 & \\
\hline \multirow[t]{2}{*}{ Tumor depth } & Superficial & 51 & 27 & 24 & 0.597 \\
\hline & Deep & 84 & 40 & 44 & \\
\hline
\end{tabular}

Sex, age, tumor size, location, and tumor depth for benign and STS patients are enumerated. Distributions were compared for each parameter using Fisher's exact test
0.0433, Mann-Whitney test). As chronic expanding hematoma growth is a long-term phenomenon, reactions in hematoma probably progress to the final fibrin degradation product (DD). High DD is useful for diagnosing chronic expanding hematoma in benign tumors. DD, PIC, SF, and TAT levels in PVNS were $0.33 \pm 0.29$, $0.53 \pm 0.23,0.43 \pm 0.23$, and $0.69 \pm 0.19$, respectively. PVNS did not exhibit significant differences in DD, PIC, $\mathrm{SF}$, or TAT relative to other benign tumors.

\section{Continuous variable logistic regression analysis of DD, PIC, SF and TAT}

Logistic regression analyses were performed to elucidate the association of multiple factors in the detection of malignancy. Univariate analysis indicated that age ( $\geq 60$ years old) (OR: 4.40, 95\%CI: 2.12-9.11, $p<$ $0.0005)$, tumor size $(\geq 10 \mathrm{~cm})$ (OR: 3.20, 95\%CI: $1.57-$ 6.54, $p=0.00143$ ) and PIC (OR: 50.9, 95\%CI: 8.70297, $p<0.0001)$ were significant factors. These factors were utilized in the subsequent multivariate analysis. Of the three factors, only PIC was determined to be a significant predictor of malignancy (OR: 24.5, 95\%CI: 3.55-170, $p=0.0012$ ). Thus, increases in PIC appear to be associated with significantly increased risk of STS (Table 3).

\section{Establishing threshold values and evaluating diagnostic accuracy}

Diagnostic accuracy for distinguishing between benign or malignant tumors was evaluated using the area under the ROC curve (AUC). Accordingly, the AUC values for PIC (0.784) and SF (0.734) were higher than for DD (0.691) and TAT (0.588) (Fig. 2). Thresholds for identifying malignant patients using DD, PIC, SF and TAT, derived from the AUC analysis using Youden's index, were determined as $0.37,0.80,0.90$ and 0.82 , respectively (Fig. 2). Threshold values for PIC and SF indicated high specificity $(0.881,0.791)$ and high positive predictive value $(0.818,0.745)$, respectively (Fig. 2, Table 4). A high degree of diagnostic accuracy for STS was observed for PIC (over 0.80) and SF (over 0.90). The highest accuracy value among the markers was observed for PIC (0.704) (Table 4).

\section{Binary variable logistic regression analysis of DD, PIC, SF and TAT}

Threshold values for DD, PIC, SF and TAT were used as binary variables in a univariate analysis. The analysis revealed significant differences in DD $(\geq 0.37)$ (OR: 4.40, 95\%CI: 2.12-9.09, $p<0.0005)$, PIC $(\geq 0.80)$ (OR: 8.26, 95\%CI: 3.44-19.9, $\mathrm{p}<0.0005)$, SF $(\geq 0.90)$ (OR: 5.74, 95\%CI: 2.68-12.3, p $<0.0005)$ and TAT $(\geq 0.82)$ (OR: 2.11, 95\%CI: $1.06-4.20, p=0.0325)$. These variables were 
Table 2 Average values of DD, PIC, SF and TAT according to patient characteristics

\begin{tabular}{|c|c|c|c|c|c|}
\hline & & DD (SD) & PIC (SD) & $\mathrm{SF}(\mathrm{SD})$ & TAT (SD) \\
\hline \multirow[t]{2}{*}{ Sex } & Male & $0.90(1.81)$ & $0.80(0.73)$ & $3.51(11.2)$ & $3.03(12.8)$ \\
\hline & Female & $0.72(1.24)$ & $0.83(0.58)$ & $3.40(9.80)$ & $1.96(4.76)$ \\
\hline \multirow[t]{2}{*}{ Age } & $<60$ & ${ }^{*} 0.39(0.86)$ & ${ }^{*} 0.59(0.51)$ & *0.84 (1.43) & *0.99 (0.89) \\
\hline & $\geq 60$ & *1.35 (2.05) & *1.09 (0.74) & *6.74 (15.2) & *4.53 (15.0) \\
\hline \multirow[t]{2}{*}{ Tumor size } & $<10$ & $* 0.64(1.54)$ & ${ }^{*} 0.72(0.70)$ & ${ }^{*} 1.30(2.15)$ & $1.30(1.56)$ \\
\hline & $\geq 10$ & *1.08 (1.62) & *0.94 (0.59) & *6.43 (15.6) & 4.29 (15.4) \\
\hline \multirow[t]{2}{*}{ Location } & Extremity & $0.85(1.77)$ & $0.74(0.49)$ & $2.51(7.03)$ & 1.45 (1.99) \\
\hline & Trunk & 0.79 (1.37) & $0.89(0.80)$ & $4.44(13.2)$ & $3.70(14.2)$ \\
\hline \multirow[t]{2}{*}{ Tumor depth } & Superficial & $0.80(1.86)$ & $0.83(0.75)$ & $3.53(10.4)$ & $1.88(3.11)$ \\
\hline & Deep & 0.83 (1.39) & $0.80(0.61)$ & $3.43(10.7)$ & $2.98(12.6)$ \\
\hline \multirow[t]{2}{*}{ Malignancy } & Benign & $* 0.52(1.40)$ & *0.55 (0.19) & *1.85 (9.66) & $2.91(13.5)$ \\
\hline & STS & *1.11 (1.70) & $* 1.08(0.84)$ & *5.06 (11.2) & $2.23(4.84)$ \\
\hline
\end{tabular}

Average values of DD, PIC, SF and TAT are shown for each parameter. ${ }^{*}$ indicates significant difference by the Mann-Whitney test $(P<0.05)$

utilized in further multivariate analysis with age and tumor size (Table 5). The multivariate analysis indicated that PIC $(\geq 0.80)$ (OR: $3.36,95 \% \mathrm{CI}: 1.19-9.43, p=$ $0.0212)$ and $\mathrm{SF}(\geq 0.90)$ (OR: $2.63,95 \% \mathrm{CI}: 1.04-6.66, p=$ $0.0404)$ demonstrated significant differences. The values for PIC (over 0.80) and SF (over 0.90) indicated that they represent suitable markers for detecting STS (Table 5).

\section{Discussion}

As soft tissue tumors have various subgroups and histological variants, pathological diagnosis is a critical tool for making objective decisions on treatment strategies. Occasionally, pathological diagnosis and differentiation between benign tumors or STS is complicated. To screen carcinoma, blood tests for CEA (carcinoembryonic antigen), SCC (squamous cell carcinoma) antigen, alpha-fetoprotein, or CA-125 are useful [7]. However, blood examinations to screen for STS have not been established. Notably, the intimate relationship between coagulation and fibrinolysis in malignant tumors is a well-known phenomenon. An association between coagulation activity, INR (international normalized ratio) and cancer prognosis, such as lung cancer, colorectal cancer, pancreatic cancer, or breast cancer, has been reported [8-12]. Increased DD in plasma is associated with poor prognosis in cancer patients such as breast cancer, renal cell carcinoma, gastric cancer, lung cancer, bladder cancers, colorectal cancers, gynecological tumors and lymphoma [5, 13-17]. Among coagulation and fibrinolysis factors, DD is one of the most reported factors analyzed as a prognostic marker. However, coagulation and fibrinolysis factors are rarely reported for distinguishing between benign and malignant tumors. Previously, we reported that fibrinogen levels were an

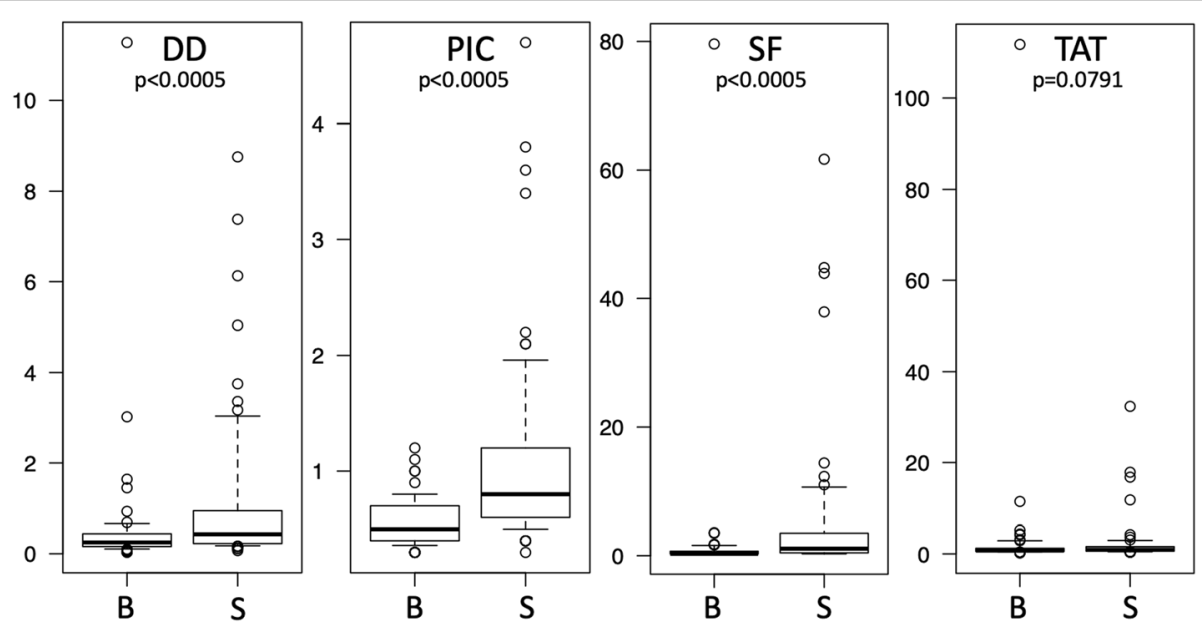

Fig. 1 Evaluation of DD, PIC, SF and TAT in patients with benign tumors or STS. DD, PIC, and SF levels were significantly higher in STS (S) than in benign (B) tumors (Mann-Whitney test) 
Table 3 Logistic analysis of continuous variables

\begin{tabular}{|c|c|c|c|c|c|c|c|}
\hline \multicolumn{4}{|c|}{ Univariate logistic analysis } & \multicolumn{4}{|c|}{ Multiple logistic analysis } \\
\hline Factor & OR & $95 \% \mathrm{Cl}$ & $p$-value & Factor & OR & $95 \% \mathrm{Cl}$ & $p$-value \\
\hline Sex (male) & 0.75 & $0.38-1.50$ & 0.429 & Age $(\geq 60)$ & 1.62 & $0.67-3.88$ & 0.282 \\
\hline Age $(\geq 60)$ & 4.40 & $2.12-9.11$ & $0.0005>$ & Tumor size $(\geq 10)$ & 1.89 & $0.82-4.29$ & 0.130 \\
\hline Tumor size $(\geq 10)$ & 3.20 & $1.57-6.54$ & 0.00143 & $\mathrm{PIC}$ & 24.5 & $3.55-170$ & 0.0012 \\
\hline Location (trunk) & 1.87 & $0.94-3.71$ & 0.0717 & & & & \\
\hline Deep & 1.25 & $0.61-1.54$ & 0.549 & & & & \\
\hline DD & 1.40 & $0.99-1.97$ & 0.0565 & & & & \\
\hline PIC & 50.9 & $8.70-297$ & $0.0001>$ & & & & \\
\hline SF & 1.04 & $0.98-1.10$ & 0.132 & & & & \\
\hline TAT & 0.99 & $0.95-1.03$ & 0.703 & & & & \\
\hline
\end{tabular}

Logistic analysis was performed to detect malignancy using continuous values of DD, PIC, SF and TAT. Multivariate analysis was performed on the significant factors identified in the univariate analysis
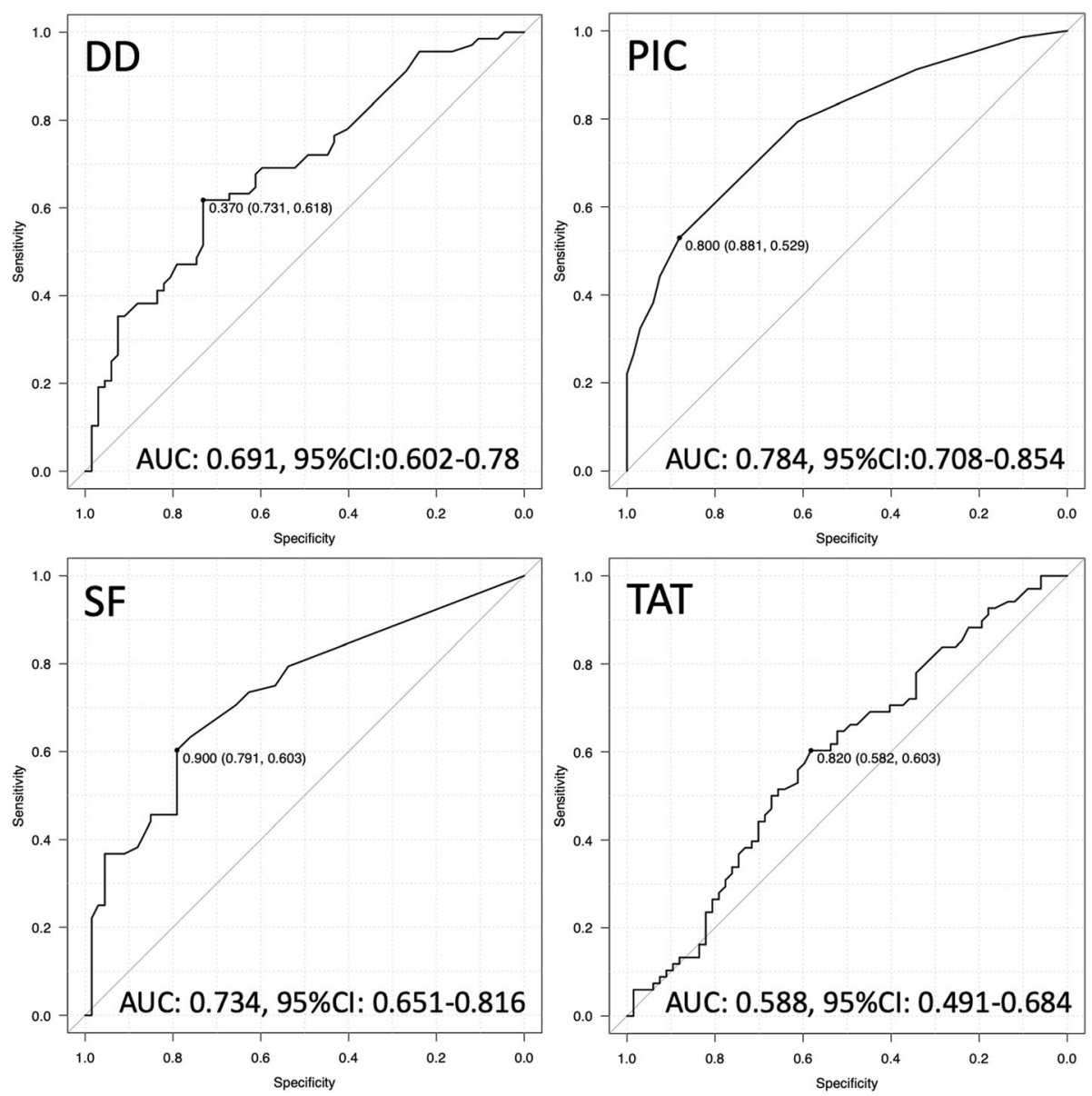

Fig. 2 ROC analysis. Thresholds values were determined by based on the Youden's index. Thresholds for DD, PIC, SF and TAT were 0.37, 0.80, 0.90 and 0.82 , respectively. Youden's index values are presented as threshold (specificity, sensitivity) 
Table 4 Accuracy evaluation of DD (D-dimer), PIC, SF and TAT

\begin{tabular}{lllllll}
\hline & \multicolumn{7}{l}{ Accuracy evaluation } & & & \\
\cline { 2 - 7 } & Sensitivity & Specificity & PPV & NPV & Accuracy & AUC \\
\hline $\mathrm{DD}(\geq 0.37)$ & 0.618 & 0.731 & 0.695 & 0.645 & 0.667 & 0.691 \\
$\mathrm{PIC}(\geq 0.80)$ & 0.529 & 0.881 & 0.818 & 0.648 & 0.704 & 0.784 \\
$\mathrm{SF}(\geq 0.90)$ & 0.603 & 0.791 & 0.745 & 0.662 & 0.696 & 0.734 \\
TAT $(\geq 0.82)$ & 0.603 & 0.582 & 0.594 & 0.591 & 0.593 & 0.588 \\
\hline
\end{tabular}

Sensitivity, specificity, positive predictive value (PPV), negative predictive value (NPV) and accuracy in detecting STS is shown, according to the threshold values of $0.37,0.80,0.90$ and 0.82

effective marker for diagnosing the differentiation of benign tumors and STS [18]. Currently, few markers are available for estimating the state of coagulation and fibrinolysis. In this study, we evaluated whether fibrinolysis markers (DD and PIC) and coagulation markers (SF and TAT) could be used to differentiate benign tumors and STS. DD is the most well-known fibrinolysis marker and has been reported as a marker capable of differentiating between benign and malignant ovarian tumors $[19,20]$. In musculoskeletal tumors, DD levels showed a potential to discriminate between welldifferentiated liposarcoma and lipoma [21]. Furthermore, PIC has been used for detecting breast cancer [22], and TAT was reported to distinguish between benign and malignant breast and ovarian tumors [20, 22]. Given these reports, coagulation and fibrinolysis markers may be more generally useful for distinguishing between benign and malignant tumors. However, there have been no reports investigating the accuracy of coagulation and fibrinolysis markers in detecting STS. Thus, the current study compares the accuracy of coagulation and fibrinolysis markers for detecting STS.

A comparison of plasma levels of DD, PIC, SF and TAT in benign tumors and STS indicated that DD, PIC and SF levels were significantly higher in STS. Additionally, logistic analysis using continuous variables indicated that PIC showed a significant difference, while the other factors did not. This indicates that increased PIC levels correspond to increased risk of STS. In contrast, univariate analysis of threshold values indicated that DD
( $\geq 0.37)$, PIC $(\geq 0.80)$, SF $(\geq 0.90)$ and TAT $(\geq 0.82)$ showed significant differences. In comparison, multivariate analysis demonstrated significant differences for PIC $(\geq 0.80)$ and SF $(\geq 0.90)$. This indicates that populations with PIC and SF levels over 0.80 and 0.90 , respectively, include many STS patients. Additionally, among the markers evaluated, PIC had a higher positive predictive value and a higher accuracy than the others. We previously reported that the AUC of fibrinogen for identifying STS was 0.805 [18]. Here, only PIC (0.784) exhibited an AUC that was roughly equivalent to fibrinogen. Thus, in order to detect STS, the PIC values over 0.80 represent the most effective marker of the four coagulation and fibrinolysis markers examined. According to previous STS studies, conversion of plasminogen to plasmin was observed on the sarcoma cell surface [23]. High expression of UPAR in tumor tissues and high levels of serum uPAR were associated with poor prognosis [24]. This indicates that fibrinolysis plays an important role in sarcoma progression. While DD generation requires both fibrin formation (coagulation) and degradation (fibrinolysis), PIC is an enzyme complex formed after plasmin generation. Thus, PIC is likely a faster and more sensitive marker of fibrinolysis activity than DD in STS patients.

In the patient population of this study, the STS group contained many elderly patients. Epidemiological studies indicate that the incidence STS increases with age [25] and an age of 52.7 years was delimited with $73.8 \%$ sensitivity and $52.3 \%$ specificity (AUC: $0.64,95 \% \mathrm{CI} 0.56-$ 0.72 ) for distinguishing benign tumors and STS [26]. In this study, an age of 55 years was delimited with $58.8 \%$ sensitivity and $71.6 \%$ specificity (AUC: $0.737,95 \% \mathrm{PI}$ $0.653-0.821$ ) by ROC analysis. Thus, age could be one of the references for the distinction of STS. Additionally, $\mathrm{DD}, \mathrm{PIC}, \mathrm{SF}$ and TAT exhibited higher values in patients over 60 years of age. It was thought that there is some association between age and DD, PIC, SF and TAT. In contrast, tumor size is a critical factor in predicting a patient's prognosis in STS. The thresholds for staging STS are 5,10 or $15 \mathrm{~cm}$, according to the 8th AJCC system. In distinguishing benign soft tissue tumors and

Table 5 Logistic analysis of binary variables

\begin{tabular}{|c|c|c|c|c|c|c|c|}
\hline \multicolumn{4}{|c|}{ Univariate logistic analysis } & \multicolumn{4}{|c|}{ Multiple logistic analysis } \\
\hline Factor & OR & $95 \% \mathrm{Cl}$ & $p$-value & Factor & OR & $95 \% \mathrm{Cl}$ & $p$-value \\
\hline $\mathrm{DD}(\geq 0.37)$ & 4.40 & $2.12-9.09$ & $0.0005>$ & Age $(\geq 60)$ & 1.56 & $0.62-3.90$ & 0.344 \\
\hline $\mathrm{PIC}(\geq 0.80)$ & 8.26 & $3.44-19.9$ & $0.0005>$ & Tumor size ( $\geq 10)$ & 1.94 & $0.84-4.42$ & 0.116 \\
\hline$S F(\geq 0.90)$ & 5.74 & $2.68-12.3$ & $0.0005>$ & $\mathrm{DD}(\geq 0.37)$ & 1.94 & $0.73-5.18$ & 0.179 \\
\hline \multirow[t]{3}{*}{ TAT $(\geq 0.82)$} & 2.11 & $1.06-4.20$ & 0.0325 & PIC $(\geq 0.80)$ & 3.36 & $1.19-9.43$ & 0.0212 \\
\hline & & & & $\mathrm{SF}(\geq 0.90)$ & 2.63 & $1.04-6.66$ & 0.0404 \\
\hline & & & & TAT $(\geq 0.82)$ & 0.71 & $0.27-1.84$ & 0.491 \\
\hline
\end{tabular}

DD, PIC, SF and TAT were converted to binary variables (high or low) according to their respective thresholds. Multivariate analysis was analyzed with age ( $\geq 60$ ) and size $(\geq 10)$ 
STS, a threshold of $5 \mathrm{~cm}$ is a weak predictor of malignancy (AUC: 0.663 , sensitivity $68.8 \%$, specificity $50.3 \%$ ) [26]. In this study, a size of $9.5 \mathrm{~cm}$ was delimited with $58.8 \%$ sensitivity and $71.6 \%$ specificity (AUC: 0.72, 95\%CI $0.636-0.805$ ) by ROC analysis. Additionally, DD, PIC and SF showed higher values in patients with tumor sizes $\geq 10 \mathrm{~cm}$. Some association between tumor size and DD, PIC and SF was considered as well as age. However, the results of the multivariate logistic analysis revealed that age and size were not significant indicators, and they did not contribute to detecting STS along with PIC or SF.

\section{Conclusion}

Of the coagulation and fibrinolysis markers studied herein, increased PIC levels were related to STS and over 0.80 PIC was the most suitable for predicting STS; thus, along with other diagnostic tools, representing a helpful subsidiary tool for predicting malignant soft tissue tumors.

The limitations of this study include that it was a retrospective study with a small number of patients. Furthermore, statistical analysis could not be performed according to each subtype because soft tissue tumors, including sarcomas, have many subtypes and the incidence rate of each is low. Many studies have resorted to analyzing STS as a whole rather than by each histological classification. Soluble DD, PIC, SF, and TAT are influenced by trauma, surgical treatment, thrombosis, and disseminated intravascular coagulation (DIC). Patients with these backgrounds were not included in the statistical analysis of this study; moreover, no patients with DIC were observed by blood test.

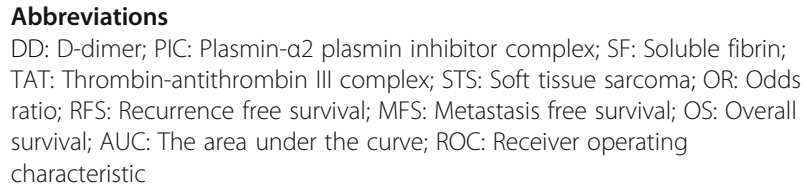

DD: D-dimer; PIC: Plasmin-a2 plasmin inhibitor complex; SF: Soluble fibrin; TAT: Thrombin-antithrombin III complex; STS: Soft tissue sarcoma; OR: Odds ratio; RFS: Recurrence free survival; MFS: Metastasis free survival; OS: Overall survival; AUC: The area under the curve; ROC: Receiver operating characteristic

\section{Acknowledgements}

Not applicable.

\section{Authors' contributions}

Research design and making manuscript: K.A. Data acquisition: K.A., T.N., T.H., K.K., K.N. Y.M. and K.Y. Data analysis: T.O. and Y.A. Drafting the manuscript and supervision: A.S. All authors have read and approved the manuscript.

\section{Funding}

The authors received no funding support for their work.

\section{Availability of data and materials}

The datasets generated and analyzed during the current study are available from the corresponding author upon reasonable request.

\section{Declarations}

Consent to publication

Not applicable.

\section{Ethics approval and consent to participate}

Written, informed consent was obtained from each patient. All patients gave consent for publication. This study was approved by the Ethics Committee of the Mie University Graduate School of Medicine (approval number: 1310). All procedures performed in studies involving human participants were in accordance with the ethical standards of the Ethics Committee of Mie University and with the Declaration of Helsinki.

\section{Competing interests}

All authors declare no competing interests.

\section{Author details}

'Department of Orthopedic Surgery, Mie University School of Medicine, 2-174 Edobashi, Tsu City, Mie 514-8507, Japan. ${ }^{2}$ Department of Pharmacology, Faculty of Medicine, Shimane University, Izumo, Shimane, Japan.

Received: 21 July 2020 Accepted: 23 March 2021

Published online: 07 April 2021

\section{References}

1. Lundbech M, Krag AE, Christensen TD, Hvas AM. Thrombin generation, thrombin-antithrombin complex, and prothrombin fragment F1+2 as biomarkers for hypercoagulability in cancer patients. Thromb Res. 2020;186: 80-5. https://doi.org/10.1016/j.thromres.2019.12.018.

2. Soe G, Kohno I, Inuzuka K, Itoh Y, Matsuda M. A monoclonal antibody that recognizes a neo-antigen exposed in the $E$ domain of fibrin monomer complexed with fibrinogen or its derivatives: its application to the measurement of soluble fibrin in plasma; 1996.

3. Kwaan HC. The plasminogen-plasmin system in malignancy. Cancer Metastasis Rev. 1992;11(3-4):291-311. https://doi.org/10.1007/BF01307184.

4. Kilıc M, Yoldas O, Keskek M, Ertan T, Tez M, Gocmen E, et al. Prognostic value of plasma D-dimer levels in patients with colorectal cancer. Color Dis. 2008;10(3):238-41. https://doi.org/10.1111/j.1463-1318.2007.01374.x.

5. Xu L, He F, Wang H, Gao B, Wu H, Zhao S. A high plasma D-dimer level predicts poor prognosis in gynecological tumors in East Asia area: a systematic review and meta-analysis. Oncotarget. 2017;8(31):51551-8. https://doi.org/10.18632/oncotarget.17936.

6. Kanda Y. Investigation of the freely available easy-to-use software 'EZR' for medical statistics. Bone Marrow Transplant. 2013;48(3):452-8. https://doi. org/10.1038/bmt.2012.244.

7. Duffy MJ. Tumor markers in clinical practice: a review focusing on common solid cancers. Med Principles Pract. 2013;22(1):4-11. https://doi.org/10.1159/ 000338393.

8. Qi Y, Fu J. Research on the coagulation function changes in non small cell lung cancer patients and analysis of their correlation with metastasis and survival. J buon. 2017;22(2):462-7.

9. Sun W, Ren H, Gao C-T, Ma W-D, Luo L, Liu Y, et al. Clinical and prognostic significance of coagulation assays in pancreatic cancer patients with absence of venous thromboembolism. Am J Clin Oncol. 2015;38(6):550-6. https://doi.org/10.1097/01.coc.0000436088.69084.22.

10. Kilic L, Yildiz I, Sen FK, Erdem MG, Serilmez M, Keskin S, et al. D-dimer and international normalized ratio (INR) are correlated with tumor markers and disease stage in colorectal cancer patients. Cancer Biomarkers. 2015;15(4): 405-11. https://doi.org/10.3233/CBM-150477.

11. Tas F, Kilic L, Serilmez M, Keskin S, Sen F, Duranyildiz D. Clinical and prognostic significance of coagulation assays in lung cancer. Respir Med. 2013;107(3):451-7. https://doi.org/10.1016/j.rmed.2012.11.007.

12. Tas F, Kilic L, Duranyildiz D. Coagulation tests show significant differences in patients with breast cancer. Tumor Biol. 2014;35(6):5985-92. https://doi. org/10.1007/s13277-014-1793-4.

13. Ay C, Dunkler D, Pirker R, Thaler J, Quehenberger P, Wagner O, et al. High D-dimer levels are associated with poor prognosis in cancer patients. haematologica. 2012;97(8):1158-64.

14. Erdem S, Amasyali AS, Aytac O, Onem K, Issever H, Sanli O. Increased preoperative levels of plasma fibrinogen and $\mathrm{D}$ dimer in patients with renal cell carcinoma is associated with poor survival and adverse tumor characteristics. In: Urologic Oncology: Seminars and Original Investigations: 2014: Elsevier; 2014. p. 1031-40. 
15. Li X, Shu K, Zhou J, Yu Q, Cui S, Liu J, et al. Preoperative Plasma Fibrinogen and D-dimer as Prognostic Biomarkers for Non-Muscle-Invasive Bladder Cancer. Clin Genitourin Cancer. 2020;18(1):11-9 e11.

16. Liu C, Ning Y, Chen X, Zhu Q. D-dimer level was associated with prognosis in metastatic colorectal cancer: a Chinese patients based cohort study. Medicine. 2020;99(7):e19243. https://doi.org/10.1097/MD.0000000000019243.

17. Liu B, Li B, Zhou P, Yue W, Wang T, Wang J, et al. Prognostic value of pretreatment plasma D-dimer levels in patients with diffuse large B cell lymphoma (DLBCL). Clin Chim Acta. 2018;482:191-8. https://doi.org/10.1016/ j.cca.2018.04.013.

18. Asanuma K, Matsumine A, Nakamura T, Matsubara T, Asanuma Y, Oi T, et al. Impact of plasma fibrinogen levels in benign and malignant soft tissue tumors. Cancer Biomark. 2016;16(3):453-8. https://doi.org/10.3233/CBM-1 60584.

19. Worasethsin P, Narkwichean A. D-dimer as a tumor marker in pre-operative assessment of adnexal masses. J Med Assoc Thail. 2013;96:1395-400.

20. Den Ouden M, Ubachs JH, Stoot J, Van Wersch J. Thrombin-antithrombin III and D-dimer plasma levels in patients with benign or malignant ovarian tumours. Scand J Clin Lab Invest. 1998;58(7):555-60. https://doi.org/10.1080/ 00365519850186175.

21. Yoshiyama A, Morii T, Tajima T, Aoyagi T, Honya K, Mochizuki K, et al. Ddimer levels in the differential diagnosis between lipoma and welldifferentiated liposarcoma. Anticancer Res. 2014;34(9):5181-5.

22. Özyllkan Ö, Baltalı E, Özdemir O, Tekuzman G, Kirazlı \$, Firat D. Haemostatic changes; plasma levels of alpha2-antiplasmin-plasmin complex and thrombin-antithrombin III complex in female breast cancer. Tumori Journal. 1998;84(3):364-7. https://doi.org/10.1177/030089169808400310.

23. Stephens RW, Pöllänen J, Tapiovaara H, Leung KC, Sim P-S, Salonen E-M, et al. Activation of pro-urokinase and plasminogen on human sarcoma cells: a proteolytic system with surface-bound reactants. J Cell Biol. 1989;108(5): 1987-95. https://doi.org/10.1083/jcb.108.5.1987.

24. Taubert H, Würl P, Greither T, Kappler M, Bache M, Lautenschläger $C$, et al. Co-detection of members of the urokinase plasminogen activator system in tumour tissue and serum correlates with a poor prognosis for soft-tissue sarcoma patients. Br J Cancer. 2010;102(4):731-7. https://doi.org/10.1038/sj. bjc.6605520.

25. Burningham Z, Hashibe M, Spector L, Schiffman JD. The epidemiology of sarcoma. Clinical sarcoma research. 2012;2(1):14. https://doi.org/10.1186/204 5-3329-2-14.

26. Gruber L, Loizides A, Ostermann L, Glodny B, Plaikner M, Gruber H. Does size reliably predict malignancy in soft tissue tumours? Eur Radiol. 2016; 26(12):4640-8. https://doi.org/10.1007/s00330-016-4300-z.

\section{Publisher's Note}

Springer Nature remains neutral with regard to jurisdictional claims in published maps and institutional affiliations.

Ready to submit your research? Choose BMC and benefit from:

- fast, convenient online submission

- thorough peer review by experienced researchers in your field

- rapid publication on acceptance

- support for research data, including large and complex data types

- gold Open Access which fosters wider collaboration and increased citations

- maximum visibility for your research: over $100 \mathrm{M}$ website views per year

At $\mathrm{BMC}$, research is always in progress.

Learn more biomedcentral.com/submissions 